\title{
Novas Tecnologias n Educação: Transformações da Prática Pedagógica no Discurso Do Professor
}

\author{
Suênia Izabel Lino Molin ${ }^{1}$, André Raabe ${ }^{1,2}$ \\ ${ }^{1}$ Mestrado em Educação \\ ${ }^{2}$ Mestrado em Computação Aplicada \\ Universidade do Vale do Itajaí - Univali \\ $\underline{\text { suenialm@gmail.com, raabe@univali.br }}$
}

\begin{abstract}
This article presents the results of a research which examined a group of teachers' perceptions about changes that occurred in their pedagogical practices after taking part in a continued formation course named "Introduction to the Digital Education". This event was promoted by the Continued Formation National Program in Educational Technology Integrated Proinfo and developed by the Educational Technology Center NTE in Itajai/SC. The results pointed out that after the participation in the course changes happened in the pedagogical practice with an increase in the technical pedagogical use of the computer and the introduction of more advanced sources. Nevertheless the research also showed that the number of teachers who use the computer in students' tasks is still small and this use is restricted to the school computer labs.
\end{abstract}

Resumo: Este artigo apresenta os resultados de uma pesquisa que investigou as percepções de um grupo de professores sobre possíveis transformações ocorridas em suas práticas pedagógicas após terem participado do Curso de Formação Continuada "Introdução à Educação Digital”, evento promovido pelo Programa Nacional de Formação Continuada em Tecnologia Educacional (Proinfo Integrado) e desenvolvido pelo Núcleo de Tecnologia Educacional (NTE) de Itajaí/SC. Os dados foram coletados por meio da aplicação de dois questionários denominados pré-curso e pós-curso. Os resultados apontaram que, após a participação nesse curso, ocorreram mudanças na prática pedagógica, com incremento no uso técnico-pedagógico do computador e introdução de recursos mais avançados. Contudo, a pesquisa também revelou que o número de professores que usam o computador nas atividades com os alunos é ainda pequeno e este uso se restringe aos laboratórios de informática das escolas.

\section{Introdução}

A utilização crescente das tecnologias de informação e comunicação (TIC) modifica nossos hábitos, modos de trabalhar, estudar e de estar no mundo, além de introduzir novas necessidades e desafios. Os computadores, ligados em rede, começam a se fazer presentes em todos os setores da sociedade, mudando as formas de comunicação, os processos de aprendizagem e o funcionamento das instituições, entre elas, a escola. 
Nessa perspectiva, as TIC precisam estar inseridas no projeto políticopedagógico das escolas (PPP) e integradas aos conteúdos curriculares, uma vez que possibilitam a ampliação das capacidades do aluno no sentido de manipulação dinâmica dos conteúdos escolares (GANDRA e GOMES, 2010), a participação ativa na construção do conhecimento e oportunidades de ensino adequadas ao período atual. Dessa forma, compreender quais as suas potencialidades e contribuições para os processos de ensino e de aprendizagem poderá trazer avanços substanciais à transformação da escola, resultando na melhoria da qualidade da educação.

Todavia, a introdução das TIC na escola traz desafios para o professor, entre eles, saber como tirar o melhor proveito delas, já que podem ser utilizadas apenas como meio para transmissão de informações ou reprodutora de práticas descontextualizadas das situações comunicativas e de aprendizagem em sala de aula. Contrário a isso, Demo (2007) argumenta que os novos recursos tecnológicos podem ser excelentes ferramentas para motivar os alunos a se tornarem autores cada vez mais interativos, críticos, criativos e ativos no processo de aprendizagem.

Nesse contexto, é primordial a criação de espaços em que os docentes possam refletir sobre o porquê e para que utilizar as tecnologias, além de proporcionar oportunidades para que desenvolvam competências que os habilitem a incorporar, criticamente, os novos recursos tecnológicos no processo pedagógico, haja vista inúmeras pesquisas comprovarem tal necessidade. Estudo desenvolvido por Cantani (2008) indica que os problemas para o uso de computadores e da internet nas atividades com os alunos iniciam com a falta de preparo adequado do professor que acaba por influir no momento de optar por integrar, ou não, as TIC às atividades escolares. Esse resultado parece culminar com recente pesquisa desenvolvida pelo Centro de Estudos sobre Tecnologias da Informação e da Comunicação (CETIC.br, 2010), que revelou que apenas $20 \%$ dos professores usam a internet em suas aulas.

Percebe-se que a introdução das TIC na prática pedagógica é um grande desafio para o professor e a origem pode estar no fato de muitos profissionais não terem ainda participado de uma formação que lhes permitisse absorver as complexidades inerentes às TIC (GANDRA e GOMES, 2010), uma vez que a utilização dessas ferramentas exige novos conhecimentos e mudanças nos processos de ensino.

Ciente dessa realidade, a Secretaria de Educação a Distância elaborou, em 2007, revisão do Programa Nacional de Informática na Educação (Proinfo), contribuindo para o surgimento do Proinfo Integrado. O programa reúne um conjunto de processos formativos, dentre eles o Curso de Formação Continuada "Introdução à Educação Digital", que visa, principalmente, familiarizar, motivar e preparar os professores da rede pública de educação básica a utilizar criticamente os recursos dos computares e da internet, disponíveis na escola, nos processos de ensino (BRASIL/PROINFO/MANUAL DO FORMADOR, 2008). O fato de o curso ser desenvolvido nos laboratórios informatizados das escolas contribuiu para o desenvolvimento de atividades que partem da vivência dos cursistas, promovendo processos de ação-reflexão-ação.

A partir da constatação dos desafios que cercam a introdução das TIC na prática pedagógica, este trabalho busca investigar as transformações ocorridas na prática pedagógica de um grupo de professores que participaram do curso de Introdução à 
Educação Digital, ressaltando a proposta desse curso, que se volta para a integração da realidade escolar, fazendo, dos cursistas, protagonistas de todo o processo de formação.

O artigo está organizado na seguinte forma: a seção 2 apresenta a metodologia adotada na pesquisa; a seção três descreve o curso "Introdução à Educação Digital" promovido pelo Proinfo Integrado; a seção 4 aborda as percepções dos professores com relação ao curso e a seção 5 discute os resultados obtidos.

\section{Metodologia da pesquisa: sujeitos, instrumentos e métodos.}

O cenário metodológico que sustentou a busca do objeto de estudo se caracterizou pela abordagem qualitativa, com dados quantitativos e qualitativos, coletados por meio da aplicação de dois instrumentos: questionário pré-curso e pós-curso. Os dados coletados pelo questionário pré-curso, composto por oito perguntas abertas e fechadas, visaram conhecer o perfil dos cursistas e saber quais eram suas expectativas em relação ao curso de formação continuada. Esses dados foram submetidos à análise de conteúdo proposta por Bardin (1977), observando-se as seguintes categorias: a) expectativas referentes ao curso de formação continuada; b) relação do professor com o computador; c) obstáculo para o uso do computador na prática pedagógica; d) objetivos a serem alcançados a partir do curso.

Já o segundo questionário, denominado pós-curso, foi composto por onze perguntas fechadas, aplicadas aos mesmos respondentes do primeiro instrumento, transcorridos aproximadamente 12 meses do encerramento do curso. Esses dados passaram por um tratamento estatístico simples e as perguntas, embora fechadas, ofereceram espaços abertos para que os respondentes pudessem justificar as opções de respostas. As perguntas foram referentes ao uso dos recursos do computador/internet na prática pedagógica e aos obstáculos encontrados pelos professores para o uso desses recursos, bem como visaram verificar quais e como os recursos tecnológicos trabalhados no curso foram introduzidos na prática pedagógica, considerando que o curso permitiu aos professores vivenciar o uso do computador, de ferramentas de edição, navegação, comunicação, interação, produção cooperativa e publicação na internet.

Os sujeitos da pesquisa foram 50 professores atuantes em escolas públicas da rede estadual de ensino, participantes do Curso de Formação Continuada "Introdução à Educação Digital", evento realizado em 27 escolas da rede pública estadual de ensino, vinculadas à Secretaria de Estado de Desenvolvimento Regional/Gerência de Educação - Itajaí/SC.

O curso teve duração de 40 horas e foi realizado nos laboratórios de informática das escolas públicas estaduais contempladas em 2007 e 2008 pelo Proinfo com computadores com sistema operacional Linux Educacional 3.0. As vagas para participação no curso priorizaram a participação dos docentes efetivos, por ser uma orientação da Secretaria de Educação do Estado de Santa Catarina.

A análise conduzida combinou o uso da estatística descritiva e de análise de conteúdo proposta por Bardin (1977) para identificar, dentre as respostas objetivas e depoimentos dos participantes, evidências sobre as possíveis mudanças em suas práticas pedagógicas ocorridas 12 meses após terem participado do curso. 


\section{O Curso "Introdução à Educação Digital"}

Introdução à Educação Digital é um curso básico ofertado aos professores da educação básica que não têm domínio do computador/internet. A proposta pedagógica foi embasada nos fundamentos da formação contextualizada, que busca envolver os docentes em questões que fazem parte da vivência diária, no uso de tecnologias como meio e não como fim, na construção do conhecimento e aplicação prática no trabalho escolar (BRASIL/PROINFO/MANUAL DO FORMADOR, 2008), o que, segundo alguns autores, possibilita uma melhor relação entre a teoria e a prática. Assim, o curso buscou familiarizar, motivar e preparar os professores para utilização crítica dos recursos tecnológicos existentes na escola, mediante reflexões sobre a importância da inclusão digital no contexto da dinâmica social e desenvolvimento de atividades práticas.

O curso foi organizado em oito unidades de estudo, distribuídos em encontros semanais de quatro horas presenciais e duas horas a distância. As atividades foram propostas e acompanhadas pelos formadores durante um período total de 40 horas de estudo e prática, quando foi oportunizado aos cursistas experimentar o uso de ferramentas de edição, navegação, apresentação, comunicação, interação, produção cooperativa e publicação na internet.

Cada unidade de estudo, prevista no caderno de estudo dos cursistas, contemplou atividades de aprendizagem, envolvendo conceitos, procedimentos, reflexões e práticas que partissem da vivência dos participantes. Essas atividades foram mediadas pelos formadores dos Núcleos de Tecnologia Educacional (NTE), que planejaram e realizaram os encontros de formação nas escolas, utilizando os laboratórios de informática, de acordo com as condições específicas de cada unidade escolar e com a demanda dos cursistas. Esse aspecto contribuiu para que os professores envolvidos com a formação trabalhassem em grupo, trocassem experiências, vivenciassem suas práticas e planejassem ações, utilizando os recursos tecnológicos disponíveis na escola em suas práticas pedagógicas. Também ofereceu a oportunidade para o gerenciamento da própria formação.

\section{Percepções dos professores: análises e conclusões}

Esta sessão está focada em conhecer a relação do professor com o computador antes e depois da participação no curso de formação continuada. Foram analisados os dados obtidos com a aplicação dos dois instrumentos da pesquisa. Buscou-se, dessa maneira, compreender a afinidade do professor com o computador a partir do conhecimento técnico e pedagógico, considerando que deste relacionamento emerge, ou não, o trabalho educativo mediado com a utilização das TIC. Entende-se que não são as tecnologias existentes na escola que irão revolucionar o ensino e, por extensão, a educação, mas sim a maneira como a tecnologia é utilizada para a mediação entre professor, aluno e informação (KENSKI, 2008).

No geral, os dados apontaram que a relação do professor com o computador, antes da participação no curso, era superficial, ficando entre o conhecimento básico e o razoável. A pesquisa mostrou que a maioria dos pesquisados (38) usavam somente os recursos mais visíveis do computador, ou seja, o editor de textos e a internet, para realizar pesquisas, além de alguns sites de interação. Esse resultado, somado ao fato de alguns professores (09) afirmarem não saber trabalhar no computador, e ainda 
considerando o registro de resistências por parte de 03 docentes, sugere limitação do emprego dessa linguagem nas atividades pedagógicas dos participantes da pesquisa. Uma possível explicação para essa questão pode ser encontrada em Moran (2008), que aponta para o fato de a maioria dos docentes fazer parte da cultura analógica e não ter tido formação que os habilitasse a trabalhar com as tecnologias digitais. Tal condição pode influenciar em sua relação com as TIC, principalmente com a inserção dessas ferramentas na prática pedagógica. Um caminho para superar essa dificuldade é apontado por Cysneiros (2003) ao concluir que o ideal é que o professor aprenda a lidar com as tecnologias da informação e comunicação durante o período de formação regular.

No entanto, a falta de habilidade do professor para inserir os recursos do computador na prática pedagógica e o registro de rejeição ao seu uso nos faz refletir sobre o histórico da inclusão da informática nos sistemas públicos de ensino. Isso porque, apesar de esse recurso já estar presente há mais de 20 anos nas escolas (VALENTE, 2011), com a distribuição de equipamentos pelo Proinfo e formação tecnológica dos professores desde 1997, as mudanças no processo de ensino estão aquém do esperado, como pode se verificar nos seguintes depoimentos dos cursistas:

Fiz um curso, mas não terminei, e não aprendi quase nada, trabalho com o computador somente quando necessário. (cursista E).

Não gosto de trabalhar com o computador, porém sei que é importante. Na verdade me viro perguntando aqui e ali. Pretendo ampliar meu conhecimento tecnológico para depois usar no meu trabalho. (cursista M).

Fiz um curso e pouco aprendi, por isso procuro sanar minhas dificuldades com a tecnologia da computação. Sei que preciso mudar minha prática. (cursista D).

Busco aprender a trabalhar com o computador, sei que é preciso incluir este recurso na minha prática para motivar mais os alunos. (cursista $G$ ).

Esses fragmentos revelam que os interesses dos professores com o curso estiveram mais voltados para o aperfeiçoamento operacional do computador em detrimento da aplicação pedagógica. Isso indica que, para os participantes, a aquisição de conhecimentos sobre o funcionamento operacional de computadores torna-se fundamental para habilitá-los a trabalhar com esse recurso na prática pedagógica.

Contudo, ressalta-se que, além da competência técnica, é imprescindível que se compreenda a importância da incorporação desse recurso na prática pedagógica para tornar o ensino mais eficiente no contexto contemporâneo. Nesse sentido, Kenski (2003) acentua que não basta ter o simples conhecimento instrucional e breve de como operar os novos equipamentos para auxiliar na tarefa de transformar a escola. É preciso, segundo Valente (2005), combinar o uso técnico com o pedagógico e, essencialmente, investir na formação inicial e continuada dos docentes, para que desenvolvam uma cultura voltada para o uso dos novos recursos e passem a incorporar o computador às atividades educativas com autonomia e criticidade, evitando usos sugeridos por apelos comerciais ou por simples modismo.

Na busca por aprofundar a questão referente à relação dos investigados com o computador, questionou-se no instrumento pós-curso sobre a frequência com que este equipamento passou a ser utilizado nas atividades com os alunos. Nesta questão, os dados, ilustrados na figura 1, apontaram que essa utilização é preocupante, pois $43,75 \%$ 
docentes disseram que nunca ou quase nunca utilizam os recursos do computador com os alunos na escola. Somente $10,42 \%$ declararam fazer um uso mais frequente, ou seja, duas a três vezes por semana. Os demais cursistas informaram utilizar apenas uma vez por semana, a cada 15 dias ou mensalmente.

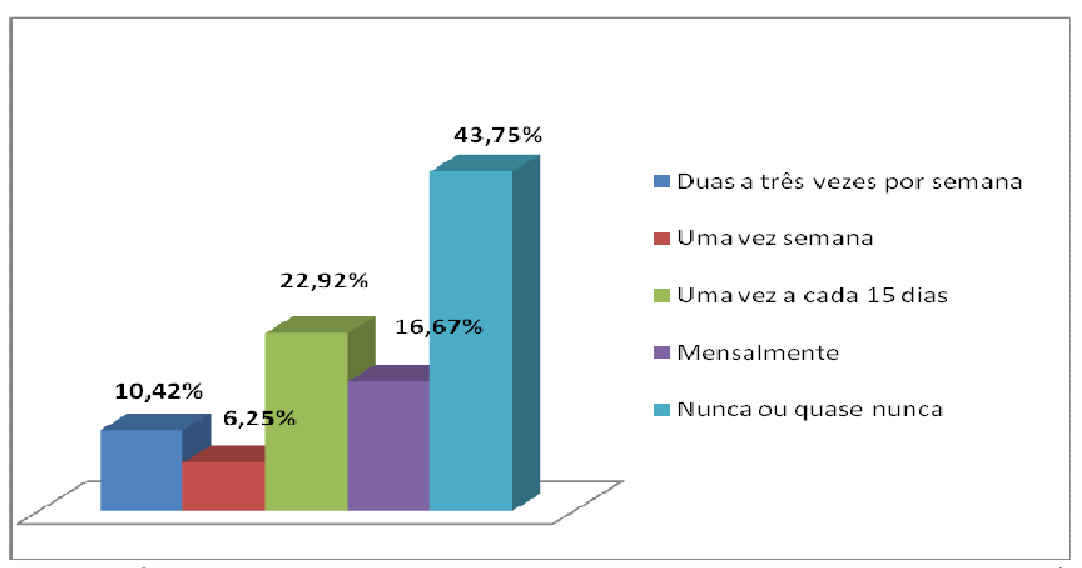

Figura 1 - Frequência da utilização do computador na escola com os alunos após o curso

Esses dados são inquietantes, pois evidenciam que, embora o curso de formação continuada "Introdução à Educação Digital" tenha primado por preparar o professor para inserir os recursos digitais no processo de ensino e aprendizagem, percebe-se que esses recursos ainda não estão significativamente incorporados na mediação pedagógica. Indicando haver limitações de uso pelos alunos na escola.

Entretanto, os resultados da pesquisa colaboram para uma possível explicação para essa questão, pois mostram que na escola existem algumas dificuldades que podem justificar a reduzida utilização do computador nas atividades com os alunos, o que significa um grande problema a ser superado, pois, como menciona Kenski (2010), os entraves para o uso das TIC resultam em impossibilidades para sua inserção no processo educativo. Mas como alerta Lampert (2004), certas justificativas - como as apresentadas a seguir - tendem a mascarar uma realidade mais evidente, ou seja, a falta de capacidade tecnológica de determinado grupo de professores.

Tenho dificuldade para conciliar o horário de aula dos alunos com a disponibilidade de horário do laboratório de informática da escola. (cursista A).

O fato dos laboratórios terem poucos computadores em relação ao número de alunos por turma gera muito tumultuo e perda de tempo. (cursista F).

A localização do laboratório dificulta o uso dos computadores, pois este fica junto à biblioteca, o que deixa esse espaço inadequado. Também há poucos computadores em relação ao número de alunos por turma. (cursista D).

Devido à necessidade de trabalhar com muitas turmas, falta-me tempo para planejar as aulas utilizando os recursos tecnológicos. Outro fato problemático diz respeito à lentidão da internet da escola e a falta de um técnico em informática para ajudar no laboratório. (cursista $G$ ).

A organização da escola por disciplina limita o horário de uso do laboratório com os alunos. (cursista E).

A análise desses relatos nos remete ao estudo de Karsent, et al (2008), que apresenta a conclusão de uma pesquisa realizada pela Organisation for Economic Co- 
operation and Development (OCDE, 2004) - Completing the foundation for lifelong learning: an $O C D E$ survey -, que reforça as falas dos professores ao apontar que o arranjo dos horários de ensino, a organização das aulas e a fraca competência técnicopedagógica dos professores impedem que as TIC sejam efetivamente integradas na pedagogia. Esse recorte nos conduz a refletir que os problemas apontados pelos investigados para inserção das TIC na prática pedagógica são vivenciados por professores também pertencentes a outras culturas. Contudo, Moran ( 2008) salienta que num mundo globalizado, que derruba barreiras de tempo e espaço, o acesso à tecnologia exige atitude crítica e inovadora e o desafio passa por criar e permitir uma nova ação docente na qual professor e alunos participam de um processo conjunto que tenha como essência o diálogo e a descoberta contínua. Portanto, partimos da análise de que não é a simples presença das tecnologias na escola que garantirá inovações pedagógicas, mas a forma como o professor as utilizará no trabalho diário é que poderá contribuir para que o ensino passe da fase da transmissão para a fase da construção de conhecimentos.

Nesse contexto, como resultado da participação dos professores no curso de formação continuada para introdução das tecnologias digitais na prática pedagógica, os dados indicam que mais de $90 \%$ dos investigados evidenciaram que o curso de formação continuada contribuiu para ampliar o domínio operacional dos professores no uso do computador, já que, dentre os 50 professores que responderam o questionário pré-curso, 41 revelaram que suas expectativas em relação às aprendizagens com o curso tinham a ver com a ampliação desse domínio. Os demais docentes manifestaram anseios relacionados a aspectos didático-pedagógicos, ou seja, almejaram aprender a usar as ferramentas tecnológicas para integrá-las no trabalho prático com os alunos.

A partir dos resultados da pesquisa foi possível observar que o evento contribuiu tanto para ampliar a capacidade do professor em manejar o computador, levando-o a utilizar com mais frequência, como para otimizar sua utilização nas atividades com os alunos, mudar a metodologia, despertar o interesse e motivação dos alunos. Isso indica que o curso colaborou para a melhoria da mediação pedagógica.

Com relação aos recursos tecnológicos apresentados no curso, percebe-se que a internet é a mais utilizada, seguida do editor de texto e do blog. Esses dados mostram que os investigados perceberam que se vive um novo espaço de comunicação, cujo potencial pedagógico é imenso se for utilizado com criticidade. Também revelam a otimização de um novo paradigma na escola, centrado na construção coletiva do conhecimento. E nesse processo o blog pode ser utilizado como espaço de construção coletiva e possibilidade de divulgação dos trabalhos escolares.

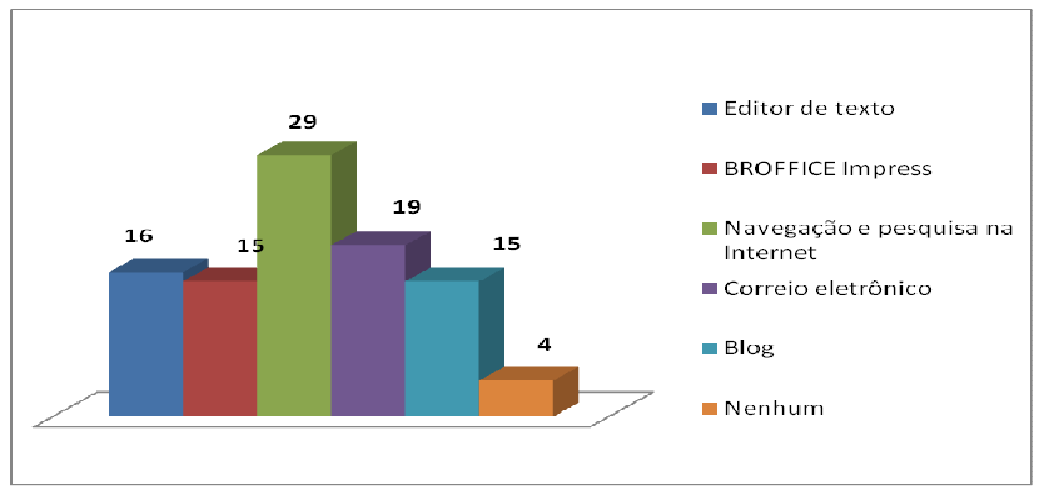

Figura 2- Recursos apresentados no curso e utilizados na prática pedagógica 
Diante dos fatos até aqui apresentados, percebe-se que o curso contribuiu para ampliar a capacidade do professor de utilizar o computador como recurso pedagógico, favorecendo a transformação da sua prática. Solicitados a expor eventuais mudanças em suas práticas após o curso, alguns professores destacaram:

Após o curso passei a usar o computador com mais frequência, tenho mais domínio dos programas e lido melhor com as questões tecnológicas. Passei a trabalhar no computador com mais segurança. Então, acho muito importante participar de cursos para o uso do computador na escola. (cursista $G$ ).

Como um número expressivo de professores de minha escola também realizou o curso além de outros membros da administração, juntos conseguimos organizar melhor o uso do laboratório de informática. Os horários foram distribuídos por turma e assim passamos a usar melhor este espaço com os alunos. (cursista $C$ ).

O curso foi importante, pois passei a estimular os meus alunos a utilizar as novas ferramentas para apresentação de trabalhos e como forma de melhorar o entendimento dos conteúdos. ( cursista J).

Ampliei e divulguei as atividades desenvolvidas na escola através da criação de um blog que foi amplamente divulgado para a comunidade escolar, inclusive na mídia. Infelizmente a partir de 2009 esse trabalho não foi mais possível devido à troca do grupo gestor da escola. (cursista A).

Observa-se no decorrer desta análise que o curso de formação continuada implicou mudanças significativas na forma como os professores passaram a se relacionar com as TIC, gerando utilização frequente dos recursos do computador/internet na prática pedagógica para pesquisar conteúdos, planejar o material didático, despertar o interesse dos alunos, usar as ferramentas da internet para divulgar trabalhos. Também contribuiu para ampliar o conhecimento operacional dos equipamentos e para inovar a mediação pedagógica, na medida em que os professores passaram a utilizar procedimentos metodológicos mais atuais nas atividades com os alunos. Contudo, alguns dados indicaram que é limitado o número de professores que utilizam o computador com os alunos e, quando esse uso ocorre, restringe-se aos laboratórios de informática da escola.

A partir dos resultados, pode-se considerar que o curso foi relevante para uma parcela representativa de professores $(97,92 \%)$, à medida que estes mostraram disposição para prosseguir aprimorando seus conhecimentos tecnológicos. Diante desse panorama, pode-se argumentar que o curso promoveu o despertar do espírito crítico em relação ao uso pedagógico das TIC, fato que levou à abertura do diálogo e à integração de novas ideias educativas.

\section{Discussão}

Os resultados desta investigação, que focou as transformações ocorridas na prática pedagógica de um grupo de professores participantes do Curso de Formação Continuada "Introdução à Educação Digital", indicaram que os professores passaram a utilizar as TIC com mais autonomia e criticidade para se comunicar, buscar informações, resolver problemas e planejar suas atividades de ensino e aprendizagem, mesmo que ainda sejam poucos os docentes que as utilizam no âmbito das atividades da sala de aula. Assim, o 
curso colaborou para incluí-los, de forma significativa, na cultura digital, uma vez que passaram a utilizar ambientes interativos e ferramentas on-line no processo pedagógico.

Contudo, os resultados sinalizaram a existência de obstáculos que limitam o uso do computador nas atividades diárias da escola. Entre os fatores para a utilização restrita foram apontados a falta de interesse do próprio professor; número insuficiente de computadores nos laboratórios de informática; falta de tempo dos professores para planejar as atividades com o uso dos recursos tecnológicos; organização curricular por disciplina; ausência de um técnico de informática para acompanhar os professores nas escolas. Esses aspectos, segundo os professores, inibem a utilização mais frequente dos novos recursos nas atividades com os alunos.

Dessa forma, considerando que a formação continuada é um fator fundamental para a introdução do computador na prática pedagógica, entendeu-se que o grande destaque do curso foi o lócus da formação, ou seja, os laboratórios de informática das escolas. Esses ambientes viabilizaram a participação ativa dos professores, fomentando o processo de reflexão, discussão e ação, atendendo as necessidades específicas das comunidades escolares e propiciando espaços para o desenvolvimento de atividades práticas que podem ser trabalhadas no processo pedagógico. Os professores construíram conhecimentos utilizando as diversas ferramentas do computador/internet de forma prazerosa, criativa e em grupo, fortalecendo suas ações. Também merece destaque a forma flexível como o curso foi concebido, oferecendo liberdade para que os formadores adaptassem a proposta pedagógica às necessidades e aos interesses dos docentes.

A análise dos dados possibilitou verificar que os cursistas satisfizeram suas expectativas iniciais em relação às aprendizagens por meio do curso de Introdução à Educação Digital, na medida em que declararam ter ampliado suas habilidades no uso do computador, adquirindo maior competência para usar os recursos da internet na prática pedagógica e incluindo a utilização de ferramentas on-line no cotidiano das aulas, bem como começaram a utilizar a internet com mais frequência para pesquisar conteúdos, atualizando os planos de aula. E assim passaram a usar os laboratórios informatizados com mais constância e autonomia, dinamizando o processo de ensino e aprendizagem.

$\mathrm{Na}$ análise do instrumento pós-curso se verificou que os professores mudaram a ação pedagógica quando passaram a usar novos recursos da informática e a divulgar na rede o trabalho desenvolvido pelos alunos na escola. Isso confirma a importância de os educandos terem um amplo e frequente acesso aos computadores ligados em rede. Dessa forma, percebe-se que os cursistas alcançaram seus objetivos prioritários em relação ao curso.

Ao apresentar tais reflexões, assinala-se a necessidade permanente de discussões sobre a contribuição da formação continuada para incorporação das TIC na prática pedagógica dos profissionais da educação, em especial da educação básica, cujos desafios são imensos. Assim, à luz dos resultados apresentados neste estudo, competenos enaltecer os cursos de formação continuada arquitetados sobre plataformas de continuidade e contextualizados com os meios e vivências dos atores, por permitirem melhor assimilação e avaliação dos progressos. Importa salientar que, embora sejam essenciais, esses fatores não são suficientes para a integração crítica das TIC na prática pedagógica. 


\section{Referências}

BARDIN, L. (1977) “Análise de conteúdo”. Lisboa, Portugal: Edições 70.

BRASIL. (2008) "Ministério da Educação". Secretaria de Educação a Distância. Programa Nacional de Formação Continuada em Tecnologia Educacional - Proinfo Integrado: Manual do formador. Brasília.

CANTANI, M. C. (2008) "Políticas públicas de formação de professores na área de tecnologias de informação e comunicação - TIC na rede pública estadual de ensino de Paraná”. 156 f. Dissertação (Mestrado em Educação) - Pontifícia Universidade Católica do Paraná, Curitiba.

CETIC.br.TIC (2010) “Educação". Comitê Gestor da Internet no Brasil.

CYSNEIROS, P. G. (2003) "Programa Nacional de Informática na Educação: novas tecnologias, velhas estruturas". In: BARRETO, R. G. (Org). Tecnologias educacionais e educação a distância: avaliando políticas e práticas. Rio de Janeiro: Quartel.

DEMO, Pedro. (2007) "Alfabetizações": desafios da nova mídia. Ensaio: avaliação de Políticas Públicas Educacionais, Rio de Janeiro, v. 15, n. 57, Dezembro.

GANDRA, A. F; GOMES, M. A. F. (2010) "Letramento digital dos professores dos anos iniciais do ensino fundamental". Anais do XVI workshop sobre informática na escola. Disponível em: http://www.br-ie.org/WIE2010/, Agosto.

KENSKI, V. M. (2003) “Tecnologias e ensino presencial e a distância”. Campinas, SP: Papirus.

KENSKI, V. M. (2010) "Tecnologias e ensino presencial e a distância”. Campinas, SP: Papirus, $8^{\text {a }}$ ed. Série Prática Pedagógica.

MORAN, J. M.; MASETTO, M. T.; BEHRENS, M. A. (2008) "Novas tecnologias e mediação pedagógica". Campinas, SP: Papirus.

OCDE. (2004) "Completing the foundation for lifelong learning”: an OECD survey of upper secondary schools. Paris.

VALENTE, J. A. (2005) "Pesquisa Comunicação e aprendizagem com o computador": o papel do computador no processo ensino-aprendizagem. In: "Integração das tecnologias na educação". Secretaria de Educação a Distância. Brasília: Ministério da Educação, Seed.

VALENTE, J. A.; ALMEIDA, F. J. (2011) "Visão analítica da informática na educação no Brasil": a questão da formação do professor. Disponível em: http://www.professores.uff.br/hjbortol/car/library/valente.html. Julho. 